\title{
Toward a theory of labor market institutions.
}

\author{
Gilles Saint-Paul ${ }^{1}$
}

November 17, 1999

${ }^{1}$ Universitat Pompeu Fabra, Barcelona, and CEPR, London. This paper is a modi ${ }^{-}$ed version of the introduction of my forthcoming book The Political Economy of labor market institutions. I am grateful to Oxford University Press for allowing this article to appear. 


\begin{abstract}
Standard economic analysis holds that labor market rigidities are harmful for job creation and typically increase unemployment. But many orthodox reforms of the labor market have proved di \pm cult to implement because of political opposition. For these reasons it is important to explain why we observe such regulations. In this paper I outline a theory of how they may arise and why they ${ }^{-} t$ together. This theory is fully developed in a forthcoming book (Saint-Paul (2000)), to which the reader is referred for further details.

J EL Classi' cation:D 7,E 24,E6,H2,J 3,J 4,J 5,J 6,K 31

Keywords: Political Economy, Labor market institutions, unemployment
\end{abstract}




\section{Introduction}

In several economies the functioning of the labor market is altered by a set of institutions that restrict the ability of private parties to freely set quantities and prices, along with a tax system that a Rects the value of working and of not working, often at the expense of the former. K ey examples include employment protection legislation, which restrict the ${ }^{-} \mathrm{rm}^{\prime} \mathrm{s}$ ability to reduce their workforce; minimum wages that put $a^{\circ}$ oor on the remuneration of labor; collective bargaining agreements that impose a rigid pay scale across skills, often compressing the distribution of wages; work rules that make it easier for incumbent employees to achieve higher wages and/ or lower working hours; unemployment bene ${ }^{-}$ts that increase the reservation wage of incumbent employees; active labor market policies where the government directly acts as a substitute for private agents in search and recruiting, etc. Furthermore, many labor market institutions come together, so that we are witnessing the co-existence of competing social models for organizing the labor market.

Standard economic analysis holds that such institutions are harmful for job creation and typically increase unemployment. This is why they are often called "rigid", a term that we shall use to refer to any regulation that reduces job creation. Most orthodox recipes against structural unemployment involve a reduction or elimination of such arrangements. But, if they hurt everybody, they would not be observed in practice. Indeed, many orthodox reforms of the labor market have proved di \pm cult to implement because of the reluctance of politicians or else because they faced - erce opposition by large or powerful sectors of society. Opposition is made worse by the recognition that the orthodox recipes ultimately call into question the social model as a whole, implying that unemployment can be cured only at the cost of a radical change. 
For these reasons it is important to explain why we observe such regulations. In this paper I outline a theory of how they may arise and why they ${ }^{-} \mathrm{t}$ together. This theory is fully developed in a forthcoming book (Saint-Paul (2000)), to which the reader is referred for further details.

\section{The role of rents}

The theory is articulated around several central concepts, the most important one being that of a rent. By rent we refer to the di ßerence between the welfare of an employed worker and that of an unemployed one, or, more precisely, by the di ßerence between what an employed worker can get from his employment relationship and his outside option, i.e. what his welfare would be outside that relationship.

The rent is one of the most appropriate measures of imperfect competition in the labor market. It tells us how far wages are from market clearing, or equivalently how remote the unemployed are from underbidding the employed successfully. A s long as the rent is positive, involuntary unemployment must arise, because in a perfectly competitive labor market any worker looking for a job could 'nd one instantaneously. In that case the welfare of the unemployed would be equal to that of the employed, and there would not be a rent.

Rents arise for two sets of reasons. First, they may arise because of microeconomic frictions that prevent wages from fully adjusting downwards in situations of involuntary unemployment. Such frictions include imperfect observability of e ${ }^{\circledR}$ ort at the ${ }^{-} \mathrm{rm}$ level; turnover costs and speci ${ }^{-}{ }^{-}$investment in the employment relationship, that create a situation of bilateral monopoly, allowing workers to extract part of the surplus generated by their job; costly search and recruiting, which is a special case of speci ${ }^{-}$c investment; impossibility of writing a complete contingent wage contract, etc. Second, there exist labor market institutions whose erect is precisely to give rise to such rents. They often do so by magnifying the microeconomic frictions; for example a 
hiring restriction would increase the cost of replacing a worker by another one, thus making him more speci ${ }^{-} \mathrm{c}$ and increasing his ability to extract part of the surplus.

Why should we expect some economies to have a greater rent, hence to be more "rigid", than others? First of all, there may be genuine di ßerences in the severity of microeconomic frictions. For example, if workers are less likely to move it may be more costly for a - $r$ to locate an appropriate worker, which in turn will increase the amount of resources spent on recruiting and therefore the surplus appropriable by the worker. Second, the rent may be high because society chooses a set of labor market institutions that generate a high rent. In such a case, the high rent arises as the outcome of political decisions. For this to be the case, it must be that those who bene ${ }^{-} t$ from the rent are numerous and/ or powerful enough. This brings the following question: how does the rent a eect the welfare of various workers?

The two main variables that determine a worker's welfare are wages and the fraction of time he expects to spend in unemployment. That fraction is smaller for the currently employed than for the currently unemployed. It depends on the two key transition rates that characterize the state of the labor market. These are the job loss rate, which we also call exposure, and the job - nding rate, also called labor market tightness. When the rent increases, each individual worker asks for a higher wage. This reduces ${ }^{-} \mathrm{rm}$ 's incentives to hire. In general equilibrium, wages must be brought in line with productivity, which means that they cannot increase by the full amount of the rent. In order to bring wages down, the outside option, or alternative wage, must fall, meaning that the unemployed are necessarily worse- 0 . Consequently, the unemployed will always be against an increase in the rent. In fact, we are able to show a more general result implying that under certain conditions the unemployed will generally favor free markets and oppose government interventions in the labor market.

Therefore, the support for rents must come from a subset of employed workers. Because the rent reduces employment, it typically reduces the job 
- nding rate and may also increase the job loss rate. This erect harms employed workers, so that if some of them gain it must be that they have greater wages. Hence we conclude that labor market institutions are supported by a group of employed workers because it allows them to increase their wages. This is exactly as if these workers were organized in a labor union that achieved monopoly power on labor supply and set wages above market clearing in the pursuit of its members' self-interest. Here, instead, workers vote for an economy-wide institution which alters the environment in which wages are set, in such a way that they expect wages to actually rise in equilibrium by enough to make them better- 0 . We refer to that mechanism as the political insider mechanism. ${ }^{1}$ Workers may be unable to coordinate in order to form a labor union, but by voting in favour of an institution that raises rents they are able to collectively achieve a higher wage level exactly as if they were organized in a union. Labor market rigidities allow insiders to monopolize the market at the economywide level even though their bargaining power may be quite reduced at the ${ }^{-} \mathrm{rm}$ level.

$J$ ust as in the case of a labor union, there must exist a favorable enough trade- $0 \AA$ between wages and employment for the political insider mechanism to give rise to enough support for the rent-raising institution. Under constant returns to scale to labor, such a trade-o ${ }^{\circledR}$ does not exist as equilibrium wages are pinned down by the marginal product of labor, which is constant. In such a case there is no support for the rent. This suggests that there must be decreasing returns to labor in order for the mechanism to be eßectivel then, a reduction in employment will be associated with a rise in worker's marginal product and therefore wages.

\section{Labor rigidities and distributive con ${ }^{\circ}$ ict}

Under what circumstances are there decreasing returns to labor at the aggregate level? Economic theory teaches us that there must be some ${ }^{-}$xed

\footnotetext{
${ }^{1}$ T his refers to the work of Lindbeck and Snower (1988), who have studied how microeconomic frictions increase incumbent employee's bargaining power.
} 
factor whose quantity does not adjust when the labor input changes. Otherwise the standard argument that one could replicate the existing production structure would automatically lead to the presumption of constant returns to scale. If there exists such ${ }^{-}$xed factors, then by reducing the amount of complementary input, wage increases redistribute from such ${ }^{-} x e d$ factor to labor, while at the same time reducing the return to the ${ }^{-}$xed factor. Hence, labor market institutions are a device to redistribute income between factors of production.

It is tempting to think that this ${ }^{-}$xed factor is capital; one would then be talking about the traditional "class struggle" between labor and capital, and labor market institutions would be one weapon that labor could use, in a democracy, to resolve that $\mathrm{con}^{\circ}$ ict in its favor. However, the main characteristic of capital is that it is not ${ }^{-}$xed, but accumulable. A ny change that reduces its remuneration, such as a decline in the complementary labor input, induces a fall in investment and a subsequent reduction in the capital stock, up to the point where the return to capital is restored to its desired level. ${ }^{2}$ Conversely, wages must have fallen back to their equilibrium level. In other words, when one takes into account the adjustment of the capital stock, in the long run everything is as if there were constant returns to labor as capital adjusts one for one to changes in employment, thus leaving wages and rates of return una rected.

For this reason we believe that the most relevant $\operatorname{con}^{\circ}$ ict that lies at the root of labor market rigidities in modern societies is that between more and less skilled workers. Any observer of European labor markets in the last thirty years of the twenty century would agree that it is a good stylized description of these markets to think of the labor market for high skill work-

\footnotetext{
${ }^{2}$ This is true in a variety of growth models. If there is perfect international capital mobility the rate of return, in the long run, cannot be di ßerent from the world rate of return, adjusted for country-speci ${ }^{-} \mathrm{c}$ factors representing risk, etc. In closed economy models such as the Ramsey model, the rate of return to capital cannot be di Berent from the rate of time preference of consumers. In the Solow model, the national savings rate pins down the capital/ output ratio in the long run, and thus wages. See Blanchard and Fischer (1989) and Romer (1995) for a discussion of growth models.
} 
ers as in equilibrium, with wages that adjust to 0 \&set demand and supply imbalances, while the low skilled labor market is in disequilibrium, with involuntary unemployment and sticky real wages. We will henceforth assume that the labor force can be partitioned in two groups, that we will label for simplicity skilled and unskilled, although by unskilled we mean a wider group than is usually referred to, i.e. the bulk of low and medium skilled workers who are most a Rected by minimum wages, employment protection and collective agreements. ${ }^{3}$ Labor market rigidities impose binding constraints on unskilled labor but not on skilled labor, whose market remains in equilibrium, so that employment of skilled labor remains essentially unchanged in response to a fall in unskilled employment. ${ }^{4}$ It is therefore reasonable to treat skilled labor as a ${ }^{-}$xed factor. ${ }^{5}$ Consequently, labor market rigidities mostly redistribute between skilled and unskilled labor.

The above discussion suggests that the political support for labor market rigidities would come from unskilled workers| and not all of them, only those who are employed. Unemployed unskilled workers and skilled workers lose from them and thus oppose it.

If this was the end of the story, societies were labor rigidities are observed would be very $\operatorname{con}^{\circ}$ ictive. Even though the group we labelled unskilled may be numerous or powerful enough to impose the institutions that suits them, we should observe constant political activity of the skilled group against such institutions. This does not sound quite realistic, and we believe that it

\footnotetext{
${ }^{3} \mathrm{At}$ the bottom there may exist a "secondary sector" of the labor market, which may be able to escape such regulations. Workers in this sector are essentially paid their outside option and for our purposes should be lumped with the unemployed.

${ }^{4}$ This obviously depends on the supply elasticity which it is reasonable to consider as small.

${ }^{5}$ It is quite interesting to study why the argument made about the adjustment of capital does not carry to the case of skilled labor. Obviously, its supply is not nearly as elastic, in the long run, as that of capital. But let us abstract from that. Consider a rise in the wages of unskilled labor, which triggers a fall in unskilled employment. Clearly, the skilled wage falls. But, at the same time, the job prospects of a worker who would enter the labor market as unskilled also fall because of the rise in unskilled unemployment. Consequently, the returns to skill need not fall, they may even rise. See Saint-Paul $(1994,1996)$ and Cahuc and Michel (1996).
} 
is because of the cohesion e eects that labor market rigidities exert upon the employed workforce.

Such cohesion eßects exist because even absent rigidities redistributive $\mathrm{con}^{\circ}$ ict would arise between skilled and unskilled workers. To the extent that the latter are poorer than the former, they have an incentive to expropriate them, i.e. to vote for any institution that results in a transfer being made to the unskilled by the skilled. They would indeed be able to impose such a transfer if they are more numerous, or more politically powerful, than the skilled| i.e., more generally, if the decisive voter is poorer than the mean.

Labor market institutions is another way to achieve such redistribution, and to a well trained economist it is a far fetched and ine \pm cient way of redistributing income, since it forces part of the workforce to be idle and excludes the poorest, i.e. the unemployed, from that redistribution. But the key point is that rigidity is supported by a very di ßerent coalition than - scal redistribution. By increasing the wage income of unskilled workers, rigidity reduces the gap between them and the skilled, thus lowering their incentives to expropriate them. As a result, part of the skilled will also support rigidity, because they recognize that less rigid institutions would intensify the redistributive con ${ }^{\circ}$ ict between skilled and unskilled workers. That is, rigidity reduces their wages but also reduces the transfer that the unskilled extract from them, and if the latter eßect is stronger than the former, they will indeed support the rigid institution.

One can show 6 that if we consider an economy with a large number of worker types, rather than just two types, the preceding argument carries through, in the sense that rigidity will typically be supported by a "middle class" of employed workers with intermediate skill levels. It will be opposed by the unemployed, who are the great losers, by the most skilled, who would gain most from an increase in the employment of complementary labor inputs, and would thus prefer to have greater wages even though they would pay more taxes, and by the poorest workers, whose wage income is so low that they

${ }^{6}$ See Saint-Paul (2000), Ch.3. 
would be better- $0 \circledR$ with greater transfers.

Therefore, while rigidity, just as ${ }^{-}$scal transfers, redistributes from skilled to unskilled workers, relative to " scal transfers they actually increase the cohesion of the middle class. The losers from rigidity| the unemployed and the two extremes of the distribution of incomel are likely to be less powerful politically than the losers from redistribution. For this reason we expect rigidity to arise even though it is an ine \pm cient way to solve the distributive con $^{\circ}$ ict between skilled and unskilled workers.

In some sense, cohesion among those who keep their jobs is increased because the poorest are excluded from the redistributive game. This alleviates the redistributive $\operatorname{con}^{\circ} \mathrm{ict}$, because those who remain in that game are made more homogenous. At the same time the total amount of resources that can be shared among the "ins" | the employed| is larger because those who have been excluded are precisely those who contributed less to the total surplus. Here we clearly see that there are two redistributive con ${ }^{\circ}$ icts going on. One is between the skilled and the unskilled workers; we call it internal con ${ }^{\circ}$ ict. The other is between the unemployed and the employed; we call it external con $^{\circ}$ ict. A key insight is that external $\operatorname{con}^{\circ}$ ict is more likely to arise, the more intense the internal con $^{\circ}$ ict, i.e. the greater inequality among employed workers. If all workers had the same marginal product, they would all contribute the same to total output, and excluding some of them would not a Bect output per capita for those who remain. By contrast, when inequality is greater, the poorest contribute much less to total output than the richest, and excluding the former substantially increases what can be redistributed to each remaining worker.

\section{W hich economic environments favour rents?}

Whether we expect rents to arise as a stable political equilibrium depends on three underlying parameters that characterize the functioning of the labor market. 
Exposure tells us how often workers expect to lose their jobs. It depends on technology, which determines the frequency at which ${ }^{-} \mathrm{rms}$ want to destroy jobs, on people's preferences and other sociological factors, which determine how often they may want to quit their jobs, and on institutional factors such as home ownership or other labor regulations such as employment protection. The lower exposure, the more the employed expect to keep their job for a long time. Exposure enters as the weight of the unemployed's welfare in the employed's welfare. When it is lower, this weight is lower because the event of becoming unemployment is more remote and thus more heavily discounted. Therefore, when exposure is lower, the employed care less about harming the unemployed and are more likely to support high rents, or more generally institutions that reduce the job ${ }^{-}$nding rate. This result tells us that we expect rent-creating institutions to prevail in societies which, for other reasons, have low labor turnover and low mobility.

Elasticity, which we de ne as the elasticity of labor demand for unskilled labor, tells us how big the scope for wage increases is when employment of unskilled workers is reduced. It is the standard parameter than intervenes in any analysis of a union's preferred wage or more generally of any monopolistic price-setting behaviour. The greater that elasticity, the less wages rise when employment of unskilled workers increase, and the lower the political support for employee rents. Elasticity is intimately linked to the degree of complementarity between skilled and unskilled workers. It is smaller, the more the two are complements in production. This tells us that rigidity is good at redistributing between groups of people who cooperate strongly in the market.

Inequality, i.e. the gap between the skilled and unskilled productivities, determines the intensity of internal con ${ }^{\circ}$ ict. As we have argued it is because of that internal $\operatorname{con}^{\circ}$ ict that it pays to the middle class coalition to opt for rigid labor market institutions. Therefore we expect that the support for rents will be greater, the greater inequality. This is actually true over some range, if inequality is low enough. But past a certain threshold inequality 
reduces the support for rents, because at high inequality levels the cost of rigidity in terms of job loss is too big.

\section{Employment protection and unemployment bene ${ }^{-}$ts}

The existence of rents acts as a catalyst for other labor market rigidities, because they increase the employed's support for such rigidities. The clearest example is that of employment protection legislation. When rents exist, losing one's job is associated with a welfare loss, precisely equal to the total rent. The employed therefore have an incentive to reduce the likelihood of job loss by means of an employment protection legislation that prevents - rms from freely reducing their workforce in a downturn. That incentive is greater, the greater the rent, i.e. the less competitive the labor market. In a perfectly competitive labor market the rent would be equal to zero and being unemployed would be equivalent to being employed because anyone could ' nd a job instantaneously at the going wage. Thus there would be no support for employment protection.

Therefore, rigidities that create rents are likely to lead to other rigidities that protect rents, which further deteriorates the competitive performance of the labor market. Furthermore, it is also true that employment protection itself increases the political support for high rents. This is because employment protection reduces exposure to unemployment, and that the employed's most desired rent is greater, as we have seen, the less exposed they are. The causality therefore goes both ways; rent-creating and rent-protecting institutions reinforce each other. We say that there is a politico-economic complementarity between the two because if one is around, the support for the other is greater. Politico-economic complementarities explain why labor market institutions come together, i.e. why we observe competing consistent social models rather than menus of institutions that span the whole space of possibilities. 
W hile complementarities are successful at explaining why rigid wages coexist with employment protection, it is harder to understand why generous unemployment bene- ts are also typically part of the picture. That is, the case in favor of politico-economic complementarities between rents and unemployment bene ${ }^{-}$ts is much weaker than for employment protection. At face value, one would be tempted to claim that in the absence of rents, there is no involuntary unemployment, and thus no need for workers to insure themselves against the unemployment risk. Closer examination, however, suggests that this is a fallacy. For when unemployment is very low, so is the ${ }^{-}$nancial cost of bene ${ }^{-}$ts, so that insurance is cheaper even though it is less desired. Indeed, if workers were voting under a veil of ignorancel i.e. not taking into account whether they are initially employed or unemployed but instead assigning an objective probability to each event based on the actual unemployment ratel they would elect full insurance regardless of the unemployment rate.

If unemployment bene- ts are merely set to provide insurance against job loss, it is essentially incorrect to treat them as a "rigidity" in the same way as minimum wages or employment protection. True, they increase unemployment, as these other institutions. But while "rigidities" typically bene ${ }^{-} t$ the employed at the expense of the unemployed, unemployment bene ${ }^{-}$ts obviously redistribute in the other direction. While the political system is likely to deliver, as we show, too much of these other rigidities relative to the social planner's optimum, it is likely to deliver too little unemployment insurance. While a reduction in exposure increases the support for rents, it reduces the employed's most preferred unemployment bene ${ }^{-} t$ level, since they care less about becoming unemployed. Finally, the ${ }^{-}$nancial burden of bene- ts reduces the scope for complementarities with other institutions: if unemployment is greater say because minimum wages are higher, the tax cost of bene ${ }^{-}$ts is larger which reduces the employed's support for unemployment insurance.

Things are di ßerent, however, if unemployment bene ${ }^{-}$ts are used by incumbent employees to achieve higher wages in equilibrium. They do so be- 
cause they increase the worker's outside option in the wage formation process. They will be used as an instrument to achieve higher wages if other institutions cannot be perfectly manipulated in order to target the employed's most preferred wage level, say if there exists some ceiling on minimum wages or on the degree of wage compression that collective agreements may specify, or some constitutional limits on work rules that can be imposed on employers. In such a case the logic of the political insider mechanism applies to unemployment bene ${ }^{-}$ts as well, and they vary in a similar way as other rigidities. The unemployed will then want less insurance (at the margin) than the employed; the political system will deliver too generous bene ${ }^{-}$ts relative to the social optimum; and lower exposure will increase the employed's most desired bene- $t$ level. Furthermore, it may well be that bene ${ }^{-}$ts are more e \pm cient at boosting wages when the rent is higher, which may generate a politico-economic complementarity between unemployment insurance and other institutions that allow insiders to achieve greater wages.

\section{The viability of labor market reform}

If, in a given country, the underlying economic conditions are such that a set of "rigid" institutions is a political equilibrium, it is foolish for an economist or an international body to recommend that they make their labor market more " ${ }^{\circ}$ exible". ${ }^{7}$ For a government who would attempt such a reform would by de nition face political opposition, and would be forced to withdraw his reform to maintain itself in power. Even if the reform was made politically viable by some clever design to compensate losers, the resulting situation would be unstable and people would soon vote for a return to the previous arrangement. The reform would only have brought turbulence and policy uncertainty, which as such may eliminate any of its positive employment

\footnotetext{
${ }^{7}$ Unless, obviously, the political support for rigidity arises from ignorance about its adverse economic e eects. In that case, however, policy recommendations are not really more needed: dissemination of economic theory and evidence should be enough.
} 
e Bects. $^{8}$

On the other hand, it may be that changes in underlying parameters makes society less willing to keep its rigid institutions. This would happen, for example, if faster technological change increased exposure; if biases in that change increased inequality in the zone where it reduces the support for rigidity; if greater international capital mobility increased elasticity; or if some innovation increased substitutability between unskilled workers and some other factor, perhaps capital, again increasing elasticity. In such a case the support for rigidity would automatically be reduced, not least because it is more costly in terms of jobs. ${ }^{9}$ If the change is strong enough then society would eventually shift from rigid to ${ }^{\circ}$ exible institutions, even absent any recommendation by economists.

The problem of reform, however, becomes more interesting if several stable outcomes may coexist. For example, underlying parameters may change in such a way that an economy which is originally ${ }^{\circ}$ exible would not want to become rigid, but that if the economy is originally rigid it will remain so, despite the fact that the support for the status-quo is lower than absent the change in underlying parameters. That is, the support for rigidity is greater if it is originally the status-quo than if it is not, i.e. there is status-quo bias.

Status quo bias implies that while the economy is in a stable political equilibrium, if reform was imposed on it by a dictator it would end up in another situation that would also be stable, i.e. once the dictator is gone there will not be su \pm cient political support to revert to the old ways. The problem of reform becomes meaningful if there is status quo bias because the economy may be locked into an "undesirable" situation (from the view point of some social welfare measure that di ßers from the decisive voter's objective) and could be led, by some properly designed reform, to a more desirable, equally stable, equilibrium. Status quo bias also implies that in-

\footnotetext{
${ }^{8}$ For a convincing example, see B ertola and Ichino (1996).

${ }^{9}$ See K rugman, 1995, for an argument that skilled-biased technical change has increased unemployment in Europe in the 1970's because relative wages have failed to adjust, although Card, Kramarz, and Lemieux (1997) 'nd a much more mixed picture.
} 
stitutions are persistent, and that di ßerent social models may be observed across two economies with similar underlying characteristics because one of them experienced some speci ${ }^{-} \mathrm{c}$ shocks in the past, which led to institutions that survived into the present even though the shock has ${ }^{-}$nally died out. ${ }^{10}$ Complementarities are likely to increase the status-quo bias, particularly if a comprehensive reform of the labor market cannot be written on the political agenda.

Status quo arises when a given set of institutions typically create their own constituency. The existence of high rents is a powerful source of status quo bias. A ny reform implies some labor reallocation, and those who expect to lose their jobs are likely to oppose the reform. Clearly, the greater the rent, the more these people expect to lose, and the greater their opposition to the reform. When rents are large, institutions may create their own constituency by maintaining a fraction of the workforce in activities that exist precisely because of that institution. This is what we call the constituency e®ect. The strength of the status quo bias generated by the constituency e eect is greater, as we saw, the greater the rent (absent rents job loss does not make the worker unhappy); it is also greater, the lower the political weight of the unemployed. The unemployed are those whose job - nding prospects are improved by change, so they provide a counterweight to the constituency of job losers; the lower their political power, the smaller that counterweight. Finally, the constituency erect generates a stronger status quo bias, the more sluggish the job creation process, because those who expect to ${ }^{-}$nd jobs because of the reform again provide less of a counterweight to those who expect to lose their jobs.

The constituency eßect is particularly prominent when one considers institutions such as employment protection. Employment protection prevents - rms from getting rid of their workers when hit by a shock that should make them obsolete. Consequently, there exists a mass of workers whose jobs would

\footnotetext{
${ }^{10}$ In Saint-Paul (1997), I speculated that the tight labor markets that Europe experienced in the post-war period eventually allowed insiders to get high rents, which eventually let to a set of rigid institutions that persisted beyond the period of tight labor markets.
} 
be instantaneously destroyed if that regulation were slashed, who provide a powerful constituency in favor of the status quo. Clearly, these workers would not exist if the economy did not have employment protection, for any job which becomes obsolete would then be instantaneously destroyed.

Worker's uncertainty about whether they will end up in the pool of losers or gainers from the reform is also likely to strengthen the status quo bias by virtue of a mechanism which we call the identi ${ }^{-}$ability e®ect. By de ${ }^{-}$nition, people know for sure their situation under the status quo, but may be uncertain about where they will end up after a reform. If the decisive voter is employed, then an increase in uncertainty typically increases his likelihood to end up unemployed as the outcome of the reform, which, as long as rents are positive, reduces his support for the reform. If the losers from the reform were perfectly identi ${ }^{-}$ed, to the extent that they are a minority the decisive voter would typically expect to keep his job, and would support the reform. It is because it redistributes losses from nondecisive to decisive voters that uncertainty increases status quo bias. In a world where the decisive voter is employed and where losers are job losers, this condition is likely to be satis ${ }^{-}$ed.

How can reform, other than implemented by a dictator, overcome the status quo bias and lift the economy from an undesirable, stable political equilibrium to a more desirable one? This is a complex topic and much research remains to be done. Let us insist on two general principles.

First, reform should be designed so as to redistribute gains from nondecisive to decisive voters. For example, reform can be made viable by means of a two-tier system that preserves the privileges of the originally employed workers while the new legislation applies only to future hires ${ }^{11}$. It is shown that the "nancial burden of such reform falls upon the ${ }^{-} r m s$ that employ the incumbent workers. Firms have zero political weight in our analysis, so that the reform design clearly redistributes gains from nondecisive agents to decisive ones. If these " $r$ ms could vote, they would not accept the reform.

\footnotetext{
${ }^{11}$ See Saint-Paul (2000), Chapter 8.
} 
A nother example is that of a reform which speci ${ }^{-}$es that the redundancies that take place during a certain period around the date of the legislative change should proceed according to some ranking of employees by seniority. Such a clause would overcome the identi ${ }^{-}$ability e eect by granting the decisive employed voter that he will not lose his job because of the reform.

Second, one can take advantage of initial conditions such that the support for the status quo is small. For example, in the case of employment protection, an economic boom reduces the share of old, obsolete jobs in total employment, and therefore the constituency against reform. Or, the support for reduction in wages may be greater at the start of a recession when the employed are more exposed to unemployment.

\section{Conclusion}

The preceding discussion sheds light on why we observe rigities in Europe and not in the U.S. This is due to the fact that the underlying parameters characterizing the functioning of the economy generate much less political support for rent-generating institutions in the U.S. than in Europe. In the United States, higher employment turnover increases the extent to which the employed internalize the unemployed's welfare in their decisions; political insider mechanisms are less favourable because greater capital mobility and sharper product market competition make labor demand inelastic; ' nally, the greater inequality of skills makes rigidity more costly in terms of jobs. Finally, in Europe the bottom of the distribution of income is traditionally better represented by political parties (such as the Communist Party) than in the U.S., where its participation in elections is quite low. This makes redistributive pressure lower in the U.S. than in Europe; therefore, the gains from rigidity that are associated with cohesion are greater in Europe than in the U.S.

These di ßerent outcomes are reinforced by the complementarities across institutions, which lead to the emergence of a "European model" distinct in 
several respects from the A merican model. Furthermore, the existence of employee rents create a severe status quo bias in Europe, via the constituency and identi ${ }^{-}$ability e eects. This explains why despite the convergence in underlying economic conditions that has taken place between Europe and the U.S. in the last decade, under the pressure of greater international economic integration and faster ${ }^{\circ}$ ows of goods, people and information, attempts to reform the labor market on this side of the Atlantic have generally faced - erce opposition from organized interest. 


\section{References}

B ertola, Giuseppe, and A ndrea Ichino (1995) "C rossing the river: a comparative perspective on Italian employment dnamics", Economic Policy, 21, October, 359-415.

Blanchard, Olivier and Stanley Fischer (1989), Lectures on macroeconomics, MIT Press: Cambridge, MA.

Cahuc, Pierre and Philippe Michel (1996), "M inimum wage Unemployment and Growth", European Economic Review; 40 (7), A ugust 1996, 146382

Card, David, Francis K ramarz and Thomas Lemieux (1995), "Changes in the relative structure of wages and employment: a comparison of the $U$ nited States, Canada, and France", Princeton University Industrial Relations Section Working paper \# 355.

K rugman, Paul (1994), "Past and prospective causes of high unemployment" , Federal Reserve B ank of K ansas City E conomic Review, 79 (4), 23-43.

Lindbeck, A ssar and Dennis Snower (1988), The Insider Outsider Theory of Employment and Unemployment, MIT Press: Cambridge, MA.

Saint-Paul, Gilles (1994) "Unemployment, Wage Rigidity, and the Returns to Education", European Economic Review, 38, 3/4, A pril 1994, 535544.

| | | | | | | (1996) "Unemployment and Increasing Returns to Human Capital", J ournal of Public E conomics, 1996, 61, 1-20.

｜｜｜｜｜（1997) "The rise and persistence of rigidities", American Economic Review, May, 87(2), 290-294.

| | | | | | | (2000) The Political Economy of Labor Market Institutions, forthcoming, Oxford University Press. 